
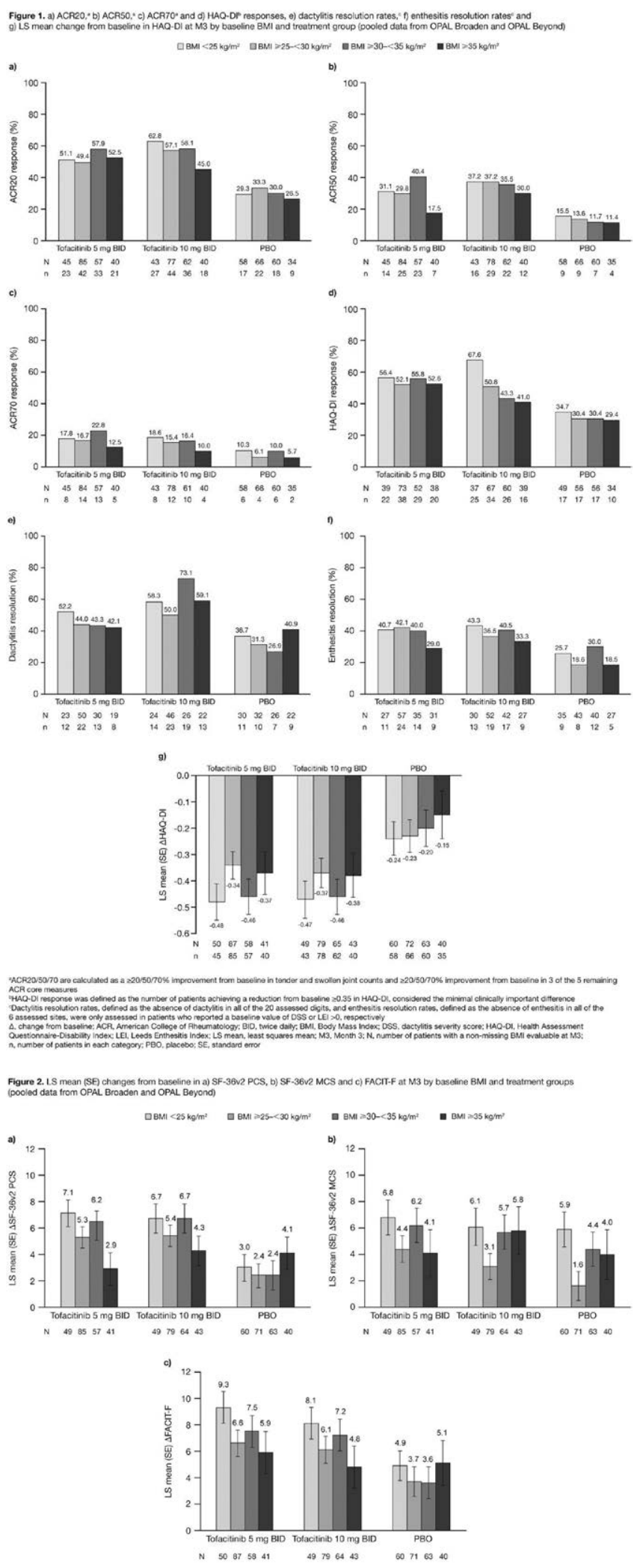

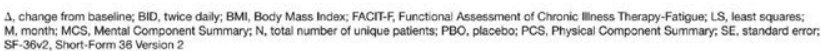

Acknowledgments: Medical writing support was provided by Mark Bennett of CMC Connect, McCann Health Medical Communications, and funded by Pfizer Inc.

Disclosure of Interests: Christopher T. Ritchlin Grant/research support from: UCB Pharma, AbbVie, Amgen, Consultant of: UCB Pharma, Amgen, AbbVie, Lilly,
Pfizer, Novartis, Gilead, Janssen, Alexis Ogdie Shareholder of: Amgen, Novartis, Pfizer Inc, Grant/research support from: Novartis, Consultant of: AbbVie, Amgen, Bristol-Myers Squibb, Celgene, Corrona, Eli Lilly, Novartis, Pfizer Inc, Jon T Giles Grant/research support from: Pfizer Inc, Juan Jesus Gomez-Reino Grant/ research support from: AbbVie, Novartis, Pfizer Inc, Roche, UCB, Consultant of: Pfizer Inc, Speakers bureau: AbbVie, Bristol-Myers Squibb, Janssen, MSD, Pfizer Inc, Roche, UCB, Philip Helliwell: None declared, Lori Stockert Shareholder of: Pfizer Inc, Employee of: Pfizer Inc, Pamela Young Shareholder of: Pfizer Inc Employee of: Pfizer Inc, Wael Joseph Shareholder of: Pfizer Inc, Employee of: Pfizer Inc, Rajiv Mundayat Shareholder of: Pfizer Inc, Employee of: Pfize Inc, Daniela Graham Shareholder of: Pfizer Inc, Employee of: Pfizer Inc, John Woolcott Shareholder of: Pfizer Inc, Employee of: Pfizer Inc, Ana Belen Romero Shareholder of: Pfizer Inc, Employee of: Pfizer Inc DOI: 10.1136/annrheumdis-2020-eular.993

\section{AB0828 $1 S$ IS PSORIATIC ARTHROPATHY DIFFERENT WHEN IS ACCOMPANIED BY AXIAL INVOLVEMENT?}

S. M. Rojas Herrera ${ }^{1}$, J. Malave Calzada ${ }^{1}$, I. Braña Abascal ${ }^{1}$, M. Priego

Fernandez-Martos ${ }^{1}$, D. Fernandez Lozano ${ }^{1}$, R. Veroz Gonzalez ${ }^{1}$, J. J. Aznar

Sanchez ${ }^{1}$, L. M. Chaves Chaparro ${ }^{1}$, E. Chamizo Carmona ${ }^{1} .{ }^{1}$ Rheumatology, Hospital of Mérida, Mérida, Spain

Background: Axial involvement in patients diagnosed of Psoriatic arthritis (PsA) in variable in previous studies. Axial involvement (according GRAPPA criteria) is based upon inflammatory spinal symptoms pain with loss of lumbar mobility and the presence of radiological sacroiliitis and other radiographic signs of spondylitis in patients with PsA.

Objectives: Evaluate the prevalence of axial involvement in PsA an their clinica features.

Methods: All patients included in the monographic PsA consultation database of our second level hospital were analyzed. Demographic, clinical and analytica variables were collected. Statistical analysis was performed using SPPSS v.25 Results: We included 145 patients with PsA (fulfilling CASPAR criteria) with a mean age at diagnosis of $45,4( \pm 13)$ years and time of evolution of the disease $9,3( \pm 6,2)$ years. The proportion of the affectation types were: peripheral $94(64,8 \%)$, mixta $31(21,4 \%)$ and axial $20(13,8 \%)$. Therefore, $51(35,2 \%)$ patients meet criteria for axial involvement, of with $31(21,4 \%)$ also had associated peripheral involvement. Table 1 shows the differences between patients with and without axial disease. Axial involvement was higher in males than women $[\mathrm{OR}=2,3(1,1-4,7), \mathrm{p}=0,023]$. HLAB27, determined in 106 patients, was more prevalent in axial PsA than in exclusive peripheral patients, $35 \%$ and $4,5 \%$ respectively [OR $=11,3(3,0-42,7), p<0,0001]$ We didn't find any differences in other domains of psoriatic disease or gender. Age at diagnosis was lower in patients with HLA B27 positive $[35,6( \pm 12,3)$ vs $46,2( \pm 12,1)$ years, $\mathrm{p}=0,0001]$ and in the patients with dactylitis $[40,2(11,8)$ vs $46,7(13)$ años, $p=0,018]$ or uveitis $[28,7(8,5)$ vs $45,8(12,8)$ years, $p=0,02]$, respect patients who did not present them, regardless of HLAB27. No differences were found in age between patients with axial o peripheral disease $[44,6( \pm 13,3)$ vs 45,9 $( \pm 12,8)$ years, $p=0,56]$, neither other domains like skin psoriasis, onicopathy or enthesitis. Patients with axial involvement had overweight (BMI >25) less frequently than peripheral disease $[O R=0,4(0,2-0,8), p=0,01)]$. We didn't find any differences in other comorbidities (arterial hypertension, diabetes hyperlipemia, hyperuricemia, ischemic heart disease, depression) between patines with axial or peripheral disease.

Table 1. Differences between axial and peripheral patterns

\begin{tabular}{lcccc}
\hline & $\begin{array}{c}\text { With axial involve- } \\
\text { ment, } \mathrm{n}=51\end{array}$ & $\begin{array}{c}\text { Without axial } \\
\text { involvement, } \mathrm{n}=94\end{array}$ & OR (IC 95\%) & p value \\
\hline Age at diagnosis, years (SD) & $44,6( \pm 13,3)$ & $45,9( \pm 12,8)$ & & 0,6 \\
Time of evolution, years (SD) & $10( \pm 6,8)$ & $8,9( \pm 5,8)$ & & 0,3 \\
Men, n (\%) & $36(42,9 \%)$ & $48(57,1 \%)$ & $2,3(1,1-4,7)$ & 0,02 \\
HLAB27, n (\%) & $14(82,4 \%)$ & $3(17,6 \%)$ & $11,3(3,0-42,7)<0,0001$ \\
Skin Psoriasis, n (\%) & $47(36,4 \%)$ & $82(63,6 \%)$ & $1,7(0,5-5,6)$ & 0,4 \\
Onicopathy, $\mathrm{n}(\%)$ & $11(26,2 \%)$ & $31(73,8 \%)$ & $0,6(0,2-1,2)$ & 0,1 \\
Dactilytis, $\mathrm{n}(\%)$ & $9(32,1 \%)$ & $19(67,9 \%)$ & $0,8(0,3-2,0)$ & 0,7 \\
Enthesitis, $\mathrm{n}(\%)$ & $13(44,8 \%)$ & $16(55,2 \%)$ & $1,7(0,7-3,8)$ & 0,2 \\
Uveitis, $\mathrm{n}(\%)$ & $2(66,7 \%)$ & $1(33,3 \%)$ & $3,8(0,3-42,9)$ & 0,2 \\
Inflammatory bowel disease, & $2(66,7 \%)$ & $1(33,3 \%)$ & $3,8(0,3-42,9)$ & 0,2 \\
$\quad \mathrm{n}(\%)$ & & & & \\
Hyperlipemia, $\mathrm{n}(\%)$ & $27(31 \%)$ & $60(69 \%)$ & $0,6(0,3-1,3)$ & 0,2 \\
BMI >25, $\mathrm{n}(\%)$ & $22(26,5 \%)$ & $61(73,5 \%)$ & $0,4(0,2-0,8)$ & 0,01 \\
Hypertension, $\mathrm{n}(\%)$ & $18(39,1 \%)$ & $28(60,9 \%)$ & $1,3(0,6-2,6)$ & 0,5 \\
Hyperuricemia, n (\%) & $16(39 \%)$ & $25(61 \%)$ & $1,3(0,6-2,7)$ & 0,5 \\
Smokers, $\mathrm{n}(\%)$ & $13(50 \%)$ & $13(50 \%)$ & $2,1(0,9-5,0)$ & 0,08 \\
Ischemic heart disease, $\mathrm{n}(\%)$ & $8(53,3 \%)$ & $7(46,7 \%)$ & $2,3(0,8-6,8)$ & 0,1 \\
Depression, $\mathrm{n}(\%)$ & $7(30,4 \%)$ & $16(69,6 \%)$ & $0,8(0,3-2,0)$ & 0,6 \\
Diabetes, $\mathrm{n}(\%)$ & $7(30,4 \%)$ & $20(74,1 \%)$ & $0,6(0,2-1,5)$ & 0,3 \\
& & & & \\
\hline
\end{tabular}


Conclusion: Prevalence of axial involvement in our cohort $(35,2 \%)$ is found within the data reported in other studies (25-70\%). Nevertheless, we found less prevalence of HLAB27 positive than other reports. Patients with HLAB27 positive, dactylitis or uveitis are diagnosed at earlier ages.

Disclosure of Interests: None declared

DOI: 10.1136/annrheumdis-2020-eular.6270

\section{AB0829 INFLAMMATORY BOWEL DISEASE IN PSORIATIC ARTHRITIS. STUDY OF 306 PATIENTS FROM A SINGLE UNIVERSITARY CENTER. PREVALENCE, CLINICAL FEATURES AND RELATIONSHIP TO BIOLOGIC THERAPY.}

L. Sanchez-Bilbao ${ }^{1}$, D. Martinez-Lopez ${ }^{1}$, N. Palmou-Fontana ${ }^{1}$, S. Armesto ${ }^{2}$ M. A. González-Gay', R. Blanco'. ' H.U. Marqués de Valdecilla, Rheumatology, Santander, Spain; ${ }^{2}$ H.U. Marqués de Valdecilla, Dermatology, Santander, Spain

Background: Inflammatory bowel disease (IBD), which includes Crohn's disease (CD), Ulcerative colitis (UC), and undetermined colitis may be related to psoriasis and psoriatic arthritis (PsA). Biologic therapy (BT) is useful in PsA and IBD but paradoxically has been related to IBD.

Objectives: In a wide series of PsA, our aim was to assess a) the epidemiologi$\mathrm{cal}$ and clinical features of associated IBD and $\mathbf{b}$ ) its relationship with BT.

Methods: All unselected consecutive patients studied in a single reference University Hospital with: a) PSA (CASPAR criteria) and b) IBD: CD, UC and undetermined colitis diagnosed by endoscopic patterns, clinical criteria and laboratory tests. A comparative study between patients with and without IBD was performed

Results: We studied 306 (165 women/141 men) patients with PsA; mean age at PsA diagnosis of $41.7 \pm 15.79$ years; delay of diagnosis from the onset of symptoms of 2.6 \pm 2.01 years. IBD $(\mathrm{CD}=6 ; \mathrm{UC}=1$ and undetermined colitis=3) was observed in 10 of 306 (3.3\%, 8 women/2 men). A significant more frequency of enthesitis, positive HLA-B27 and non-significant more severe PsA (axial, and hip involvement, and a higher BASDAI, BASFI, DAPSA, PASI) was observed in patients with associated-IBD (TABLE).

IBD was present before PSA in 5 patients and in the other 5 , after $9.6 \pm 15.3$ years of evolution of PsA. BT for PsA has been used in $1(20 \%)$ (etanercept) of these 5 patients which developed IBD and in 67 of $296(22.6 \%)$ without IBD (Adalimumab 45; Certolizumab 8; Infliximab 6; Golimumab 4; Etanercept 4).

Conclusion: IBD in PsA was uncommon (3.3\%), may be associated to a more severe PsA, and no relationship to BT was found.

TABLE 1.

\begin{tabular}{|c|c|c|c|}
\hline & $\begin{array}{l}\text { Patients with IBD } \\
(n=10)\end{array}$ & $\begin{array}{l}\text { Patients without IBD } \\
\qquad(\mathrm{n}=296)\end{array}$ & p \\
\hline \multicolumn{4}{|l|}{ DEMOGRAPHIC PARAMETERS } \\
\hline Sex, n (\%) & 2 o/8 $9(20.0 / 80.0)$ & 139 o/157 o (46.9/53.1) & $p=0.11$ \\
\hline $\begin{array}{l}\text { Age at PsA symptoms onset } \\
\text { (years), mean } \pm \text { SD }\end{array}$ & $39.0 \pm 15.1$ & $44.2 \pm 11.4$ & $p=0.17$ \\
\hline Age at PsA diagnosis, mean \pm SD & $41.7 \pm 15.7$ & $46.4 \pm 15.8$ & $p=0.22$ \\
\hline \multicolumn{4}{|l|}{$\begin{array}{l}\text { PsA RELATED DATA } \\
\text { PsA type }\end{array}$} \\
\hline Asymmetric Oligoarticular, n (\%) & $4.0(40.0)$ & $159(53.7)$ & $p=0.59$ \\
\hline Symmetrical Polyarthritis, n (\%) & $0.0(0.0)$ & $46(15.5)$ & $p=0.37$ \\
\hline Axial, n (\%) & $3.0(30.0)$ & $40(13.5)$ & $p=0.31$ \\
\hline Mixed, n (\%) & $3.0(30.0)$ & $51(17.2)$ & $p=0.54$ \\
\hline Enthesitis, n (\%) & $7.0(70.0)$ & $111(37.5)$ & $\mathrm{p}=0.03^{*}$ \\
\hline Dactylitis, n (\%) & $0.0(0.0)$ & 79 (26.7) & $p=0.70$ \\
\hline Hip involvement n (\%) & $4.0(40.0)$ & 55 (18.5) & $p=0.57$ \\
\hline \multicolumn{4}{|l|}{ Scores } \\
\hline BASDAI, median [ICR] & $3.1[0.0-4.4]$ & $2.2[0.0-4.5)$ & $p=0.64$ \\
\hline BASFI, median [ICR] & $6.0[0.0-6.9]$ & $0.0[0.0-3.3]$ & $p=0.69$ \\
\hline DAPSA, median [ICR] & $10.7[0.0-14.62]$ & $4.3[0.0-13.0]$ & $p=0.31$ \\
\hline PASI, median [ICR] & $2.3[0.0-6.7]$ & $0.6[0.0-2.38]$ & $p=0.70$ \\
\hline Laboratory tests: HLA-B27, n (\%) & $6.0(60.0)$ & $23(7.8)$ & $p=0.001^{*}$ \\
\hline
\end{tabular}

Disclosure of Interests: Lara Sanchez-Bilbao Grant/research support from: Pfizer, David Martinez-Lopez: None declared, Natalia Palmou-Fontana: None declared, Susana Armesto: None declared, Miguel A González-Gay Grant/ research support from: Pfizer, Abbvie, MSD, Speakers bureau: Pfizer, Abbvie, MSD, Ricardo Blanco Grant/research support from: AbbVie, MSD, and Roche, Speakers bureau: AbbVie, Pfizer, Roche, Bristol-Myers, Janssen, and MSD DOI: 10.1136/annrheumdis-2020-eular.4806

\section{AB0830 LIPID PROFILE IN PSORIATIC ARTHRITIS. FREQUENCY AND ASSOCIATION WITH DISEASE ACTIVITY.}

V. Savio ${ }^{1,2}$, Y. Tissera ${ }^{1}$, M. I. Quaglia ${ }^{1}$, J. A. Albiero ${ }^{1}$, C. G. Alonso ${ }^{1}$ M. Demarchi' ${ }^{1}$, C. Maldini ${ }^{2}$, C. Gobbi ${ }^{1,2}$, M. Yorio $^{1,2}$, A. C. Martini ${ }^{2}$, M.

E. Castrillon ${ }^{3}$, P. Alba $^{1,2}{ }^{1}$ Hospital Córdoba, Córdoba, Argentina; ${ }^{2}$ Universidad Nacional de Cordoba, Córdoba, Argentina; ${ }^{3}$ Hospital Italiano de Cordoba, Cordoba, Argentina

Background: Psoriatic arthritis (PsA) is a chronic inflammatory disease associated with higher risk of cardiovascular events and metabolic syndrome. The inflammation not only accelerates atherosclerosis, but also may influence cardiovascular $(\mathrm{CV})$ risk factors such as lipid profile, blood pressure and insulin resistance. Lipid profile has previously been studied in PsA, however this association is still controversial.

Objectives: To study the frequency of altered lipid profile in patients with PsA and its association with disease activity.

Methods: We studied all the patients with diagnosis of PsA who consecutively attended to Rheumatology Unit at Cordoba Hospital from July 2018 to December 2019. PsA was diagnosed according CASPAR criteria. Clinical and laboratory data were collected. The activity of the disease was evaluated by PASI, MDA and DAPSA. Quantitative variables will be expressed in median and 1st and 3rd interquartile; qualitative variables expressed in frequency and percentage. Correlation analysis was calculated using Spearman's rank correlation coefficient. $\mathrm{P}<0.05$ was considered statistically significant.

Results: 42 PsA patients were included. Mean age was 56 years old $(47.25-62.75)$ and $54.76 \%$ were female $(n=23) .92 .86 \% \quad(n=39)$ of the patients had plaque Psoriasis and $87.8 \%(n=36)$ had peripheral joint involvement.

Frequency of comorbidities in PsA are shown in Graphic 1. 31 (73.8\%) of the patients were treated with topical therapy, $3(7.14 \%)$ with phototherapy, $31(73.8 \%)$ with Methotrexate and $17(41.46 \%)$ with biologics and JAK inhibitor. Activity Disease Index and Lipid profile are shown in Table 1 and 2 .

There was not association between Apo B/Apo A coefficient with DAPSA (rho=0.013; $\mathrm{p}=0.940$ ) and MDA (rho=-0.029; $\mathrm{p}=0.867$ ).

Conclusion: In spite of the presence of cardiovascular factors in the majority of PsA patients, lipid profile is not correlated with disease activity in this population.

References:

[1] Ahlehoff O, Gislason GH, Charlot M, et al. Psoriasis is associated with clinically significant cardiovascular risk: A Danish nationwide cohort study. $J$ Intern Med 2011:270:147-57.

[2] Mallbris, L., Ritchlin, C.T., Ståhle, M. "Metabolic disorders in patients with psoriasis and psoriatic arthritis." Curr RheumatolRep.8(5): 355-363. 2006

[3] Ng CY, Tzeng I-S, Liu S-H, Chang Y-C, Huang Y-H. Metabolic parameters in psoriatic patients treated with interleukin-12/23 blockade (Ustekinumab). J Dermatol 2018; 45:309-313

[4] Kaur S, Kingo K, Zilmer M. Psoriasis and cardiovascular risk - do promising new biomarkers have clinical impact? Mediators Inflamm 2017; 2017 : 7279818

[5] Gentile M, Peluso R, Di Minno MN, et al. Association between small dense LDL and sub-clinical atherosclerosis in patients with psoriatic arthritis. ClinRheumatol 2016; 35: 2023-9.

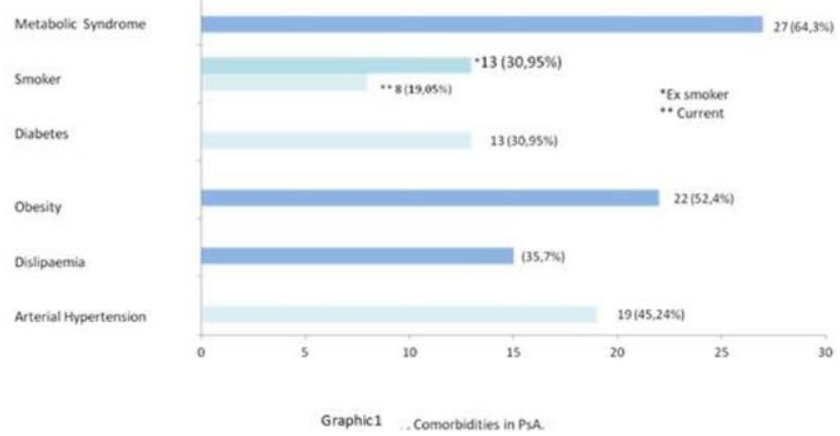

Graphic 1. Comorbidities in PsA 